\title{
PESQUISAS BRASILEIRAS SOBRE PROFESSORES INICIANTES NA CARREIRA: CONTRIBUIÇÕES PARA O CAMPO DA FORMAÇÃO DE PROFESSORES
}

Investigación brasileña sobre profesores principiantes en la carrera: contribuciones al campo de la formación de profesores

Brazilian research on beginning teachers in the career: contributions to the field of teacher training

Deise Ramos da Rocha*

https://doi.org/10.38117/2675-181X.formov2020.v2i2n4.537-555

\section{RESUMO}

A investigação se pauta na emergência de estudos e proposições sobre o professor em início de carreira, como proposta de contribuição para o campo da formação de professores. Desta forma, este trabalho justifica a necessidade em conhecer as investigações lançadas sobre o início da docência, as metodologias, o referencial teórico e as temáticas investigadas, como forma de aprofundar os estudos, lançar críticas e apontar lacunas investigativas. A partir dos dados encontrados em uma revisão bibliográfica realizada no banco de dados de teses e dissertações do Instituto Brasileiro de Informação em Ciência e Tecnologia (IBICT), em anais de eventos e em periódicos Qualis A e B, abarcando o recorte temporal de 2000-2014. Algumas lacunas de estudos são constatadas, dentre as quais se destaca o pouco investimento na formação continuada e carreira dos professores da educação básica, em diálogo com uma formação humanizadora.

PALAVRAS CHAVE: Formação de professores; Professor iniciante; Revisão literária.

\section{RESUMEN}

La investigación se basa en la aparición de estudios y propuestas sobre el profesor al comienzo de su carrera, como una propuesta para contribuir al campo de la formación del profesorado. Por lo tanto, este trabajo justifica la necesidad de conocer las investigaciones iniciadas al comienzo de la enseñanza, las metodologías, la referencia teórica y los temas investigados, como una forma de profundizar los estudios, lanzar críticas y señalar lagunas investigativas. A partir de los datos encontrados en una revisión bibliográfica realizada en la base de datos de tesis y disertaciones del Instituto Brasileño de Información en Ciencia y Tecnología 
(IBICT), en los anales de eventos y en las revistas Qualis A y B, que abarcan los años 2000-2014. Se observan algunas lagunas de estudio, entre las cuales se destaca la baja inversión en educación continua y la carrera de los maestros de educación básica, en diálogo con una formación humanizadora.

PALABRAS CLAVE: Formación del profesorado; Maestro principiante; Revisión literaria.

\begin{abstract}
The investigation is based on the emergence of studies and propositions about the teacher at the beginning of his career, as a proposal to contribute to the field of teacher education. This work justifies the need to know the investigations launched on the beginning of teaching, the methodologies, the theoretical reference and the themes investigated, as a way to deepen the studies, launch criticisms and point out investigative gaps. From the data found in a bibliographic review carried out in the database of theses and dissertations of the Brazilian Institute of Information in Science and Technology (IBICT), in annals of events and in Qualis A and B journals, covering the 2000- 2014. Some study gaps are noted, among which the low investment in continuing education and the career of basic education teachers stands out, in dialogue with a humanizing formation.
\end{abstract}

KEYWORDS: Teacher training; Beginning teacher; Literary Review.

\title{
Introdução
}

Este artigo tem por objetivo apresentar uma revisão literária em pesquisas brasileiras que investigam o início da carreira docente, com a finalidade de conhecer a empiria dos trabalhos publicados em diversos lócus, e contribuir para o campo científico da Formação de Professores. Cabe evidenciar que esta pesquisa é desenvolvida no âmbito do trabalho coletivo do Grupo de Estudos e Pesquisas sobre a Formação e Atuação de Professores/Pedagogos - GEPFAPe, e integra parte de nosso trabalho apresentado na dissertação de mestrado (ROCHA, 2016).

A busca pelas pesquisas foi realizada por palavras-chave: professor iniciante, professor ingressante, professor principiante, socialização profissional, aprendizagem da docência, iniciação profissional, anos iniciais de exercício da profissão, desenvolvimento profissional, desenvolvimento profissional no início da carreira, desenvolvimento profissional docente e professor iniciante. A seleção dos trabalhos foi feita pela leitura dos títulos e subtítulos, palavras-chave e resumos, seguido da leitura dos trabalhos 
encontrados e pontuando questões importantes para nosso campo, quanto ao tema desenvolvido nas pesquisas, região de realização da pesquisa, abordagem e metodologias, autores utilizados. Para compreender melhor a temática, realizamos um estudo prévio de autores que abordam o desenvolvimento profissional docente, o qual é apresentado uma síntese aqui, relacionando com nossa lente lançada sobre os dados.

\section{Desenvolvimento Profissional e Aprendizagem da Docência}

Iniciando nossa tarefa em contextualizar o entendimento ao termo desenvolvimento profissional docente, sentimos a necessidade, antes de adentrar na especificidade da docência, em matutar sobre o termo desenvolvimento trazendo o significado de evolução e continuidade (VAILLANT e MARCELO, 2012), que se transpõe entre a formação inicial e o aperfeiçoar das competências profissionais. Assim, entendemos que o desenvolvimento profissional integra, em si, experiências de aprendizagens - planejadas, conscientes, carregada de proposições intencionais e objetivas, por demandar a melhoria na qualidade do exercício profissional. Conforme Vaillant e Marcelo (2012, p. 168) propõem, "desenvolvimento profissional é antes de tudo aprendizagem".

esta forma, a aprendizagem incutida no desenvolvimento profissional docente remete ao trabalho, ao trajeto percorrido na carreira, as condições de trabalho, ao exercício profissional, e está totalmente relacionado com a formação docente - inicial e continuada. Sob nossa lente, o desenvolvimento profissional docente é pertencente a uma totalidade de fenômenos que condicionam a progressão na carreira. Implica a interação com os contextos espacial e ambiente social (no qual as condições de trabalho vão influenciar diretamente, de forma que promova ou iniba o seu desenvolvimento) e temporal (apregoado ao tempo de exercício profissional).

Os fatores da temporalidade e o ambiente social têm sido caracterizados pela distância em relação às necessidades dos docentes, ambiente de trabalho e sujeitos com que trabalham, parte característica do fenômeno aparente revelado pela pseudoconcreticidade que o sistema capitalista tenta limitar: essa é uma forma política de não se responsabilizar pela educação, incumbindo ao professor em lidar com a pressão do chamado fracasso escolar, e continuar recolhendo os benefícios de uma mão de obra preparada para movimentar o mercado de exploração do trabalho. Fala-se em mão de obra qualificada de acordo com as necessidades das produções mercantis capitalistas. Os objetivos para uma formação da aprendizagem da docência "não é absolutamente fornecer-lhe um conjunto de indicações práticas, mas armá-lo de modo que ele próprio seja capaz de criar um bom método, baseando-se numa teoria sólida de pedagogia social" (PISTRAK, 2008, p. 25). 
Nesta relação, se revela também um projeto de formação de professores, que prioriza o ensino de conteúdos sistemático pelo conteúdo sistemático, sem fazer qualquer relação com a ciência e o conhecimento produzidos pelo homem/mulher no decorrer da história, e a relação com as estruturas sociais, e com o trabalho humano. Há um projeto de formação do homem/mulher reprodutor de ideais ideologicamente localizados, e que escondidos na moral e na legalidade que permeia o cotidiano escolar e as políticas públicas que o organiza, mantém um estreitamento de possibilidades de transformação social, e a reprodução de relações que mercantilizam o homem e suas atividades.

A perspectiva de interferir no desenvolvimento e aprendizagem da docência está em justamente romper com maquinismos e a naturalização que estão postas de dificuldades e sofrimento, ligados ao saber e competência do lidar com o conhecimento, quando na realidade, são as estruturas relacionadas ao tempo de serviço e ambiente social de trabalho e formação, que revela em si muitas outras questões objetivas de controle do trabalho docente, escondidos nos fenômenos.

Assim, estudar a formação de professores no desenvolvimento profissional da carreira, requer nosso olhar para o estudo dos fenômenos a que estão postas as relações com que os docentes lidam no seu cotidiano.

[...] é preciso estudar os fenômenos em suas relações, sua ação e dinâmica recíprocas, é preciso demonstrar que os fenômenos que estão acontecendo na realidade atual são simplesmente partes de um processo inerente ao desenvolvimento histórico geral, é preciso demonstrar a essência dialética de tudo o que existe, mas uma demonstração deste tipo só é possível na medida em que o ensino se concentre em torno de grupos de fenômenos constituídos em objetos de estudo (...) trata-se de uma questão que se relaciona com a essência do problema pedagógico, com o conhecimento dos fenômenos atuais em suas relações e dinâmica recíprocas (PISTRAK, 2008, p. 35).

Pensar na aprendizagem incutida no desenvolvimento profissional docente requer um posicionamento político e ideológico de centrar a formação do professor, projetada a partir das condições de trabalho e da classe, público que frequenta o espaço escolar, como aluno. Mas não somente o pensar a partir de uma dita escuta sensível, e sim tornar o professorado autor e sujeito das políticas pensadas para a formação docente. Esse seria um movimento verdadeiro de esforço em investir na qualidade da atuação da profissão, na qual toda a base "do trabalho escolar devem estar o estudo do trabalho humano, a participação nesta ou naquela forma de trabalho, e o estudo da participação das crianças no trabalho" (PISTRAK, 2008, p. 50).

Segundo as fontes levantadas por Hubermam (2000), os estudos sobre a carreira de professores têm seu início na década de 1970, nos Estados Unidos da América e Inglaterra, e a continuidade de seu desenvolvimento no que podemos chamar de fase 
inicial de investigação sobre o tema, no decorrer da década de 1980, nos EUA, Inglaterra, Países Baixos, Austrália, França, e Canadá. O autor aponta que até este período, os estudos se limitavam à formação inicial e à fase principiante na carreira. Trazendo seu estudo à tona, e estipulando como base para entender o nosso objeto, este trabalho concebe os três primeiros anos como recorrentes à fase inicial da carreira docente, em que o sujeito vivenciará o contato inicial de forma homogênea, passando pelo estágio de sobrevivência e descoberta.

Inferimos que a inserção à docência pode percorrer por vários anos, e que esta fase está ligada ao desenvolvimento de sua identidade como docente, dentro do contexto do espaço escolar, onde, de forma mais amadurecida, assume o papel que a carreira lhe incube. Porém, como no Brasil, a efetivação no serviço público, segunda a Lei $n^{\circ}$ 8.112/90 ${ }^{1}$, e que os Estados decorrem em seguir em suas legislações, o estágio probatório para todo servidor que ingressa no serviço público é de três anos recorrentes.

Esse estágio impacta na segurança e confiança que o professor vai adquirindo, após essa etapa, além de ser a fase em que o docente vivencia e experimenta as primeiras experiências, dada a heterogeneidade do corpo estudantil e das condições de trabalho, com maiores doses de incerteza e estresse (VAILLANT e MARCELO, 2012), pelo fato de que há menos referências e mecanismos para enfrentar as situações. Em outras palavras, o docente tem poucas experiências diante de uma diversidade de situações vivenciadas de formas intensificadas, diante das condições de trabalho com que os novos professores iniciam o exercício profissional.

Também é nesta etapa que o professor faz a transição da posição de aluno, da formação inicial para o ingresso ao mundo do trabalho agora, como profissional apto a exercer a profissão. Por isso, uma preocupação com o aprender a ensinar. Esta etapa está relacionada com a aprendizagem experimental e ativa, necessitando ser diferenciada da imitação ou da aplicação de desenvolturas pedagógicas. Conforme já citamos, a fase inicial do desenvolvimento da profissão está totalmente imersa na construção e afirmação de uma perspectiva do trabalho docente. Acompanhar o docente nesta etapa da carreira se faz fundamental para a constituição basilar de uma para o professor que está aprendendo a profissão.

Aprendemos a ser docentes quando somos conscientes do que fazemos e do por que o fazemos; quando damos razões e refletimos sobre as origens e consequências de nossas condutas e das dos demais [...] Os docentes principiantes necessitam ter um conjunto de ideias e habilidades críticas, assim como a capacidade de refletir, avaliar e

${ }^{1}$ Lei Federal no 8.112 , de 11 de dezembro de 1990, que dispõe sobre o regime jurídico dos servidores públicos civil da União, das autarquias e das fundações públicas federais. Disponível em <http://www.planalto.gov.br/ccivil_03/leis/18112cons.htm>. 
aprender sobre seu ensino, de tal forma que melhore, continuamente como docentes (VAILLANT e MARCELO, 2012, p. 92 e 127).

A partir dos estudos de Hubermam (2000), exploramos as considerações já apresentadas pelo autor, sobre sete fases da carreira docente. Situando, o autor chega aos tais resultados por uma abordagem sociológica, mas que não exclui a abordagem psicológica, com base em estudos realizados com outras carreiras. É feita, então, uma relação cronológica de comparação entre o exercício nas sete diferentes fases:

1. A entrada na carreira: A fase se remete ao contato inicial do professor iniciante com o chão do exercício profissional. Esse é um estágio de sobrevivência e descobertas, onde são vivenciadas o choque de realidade, o confronto com as complexidades da condição de trabalho docente, sobretudo, com o social, o pedagógico e o didático. Nesta fase, as descobertas revelam um entusiasmo inicial, de experimentações e exaltações, e responsabilidades por estar na situação como professor. Paralelamente, vivenciadas com descobertas que permitem o professor aguentar esta fase de sobrevivência às dificuldades.

2. Estabilização: Esta fase se caracteriza como a fase da escolha da identidade profissional, como parte decisiva no desenvolvimento profissional, como também para a escolha das renúncias da profissão - podendo resultar no abandono da profissão. Mas também pode representar a chegada à estabilidade, precedido ou acompanhado pelo sentimento de competência pedagógica.

3. Diversificação: Fase de construção do que abordar da prática docente, e como se portar em sala de aula. Conduz a uma fase de experimentações e diversificações. Nesta etapa é demonstrado um entusiasmo pela profissão e o comprometimento com atividades dadas coletivas, aplicadas tanto na prática pedagógica, quanto no desenvolvimento do trabalho junto aos demais colegas profissionais.

4. Questionamento de si: Esta fase condiz ao meio da carreira, em que os parâmetros sociais - instituição, contexto político ou econômico, vida familiar são fatores determinantes na disposição da atuação profissional. Os estudos apontam diferenças sentidas entre homens e mulheres - em que, na perspectiva de nosso olhar, o biológico tem um peso diferenciado do social, porém, ambos estão relacionados por questões culturais da sociedade.

5. Serenidade e distanciamento afetivo: Nesta fase, os estudos apontam para uma notificação de baixo ou falta de entusiasmo para com o exercício do trabalho. Este, tende a tornar-se mecânico, mesmo com as diversidades tão 
presentes no ambiente escolar. A distância entre o início da carreira até o caminho percorrido sofre uma redução abatedora. Também fica nítida uma diferença na relação com os alunos, ocasionado pela diferença entre idade, sobrecarregando um distanciamento na relação professor-aluno.

6. Conservantismo e lamentações: Diferente da etapa anterior, esta fase demonstra uma serenidade, e nos atreveríamos em dizer, amadurecimento, no qual, o professor pode chegar aqui pelo percurso de vários caminhos.

7. Desinvestimento: Essa última fase é marcada por um fenômeno recuador e de interiorização do percurso feito na carreira. Há um libertar-se das responsabilidades da carreira, sem lamentações, para se dedicar aos interesses próprios.

O autor ainda faz relação temporal com o tempo de carreira, possível de ser relacionado à idade do sujeito. Essas fases, em nosso entendimento e discussões levantadas no contexto do GEPFAPe, condizem e divergem com as fases vivenciadas pelos professores atuantes na realidade brasileira, dada as condições de trabalham que são alarmantes, conforme o estudo de Oliveira e Vieira (2012) constata sobre as condições e precariedades do trabalho docente em sete estados brasileiros, compreendidas como as principais causas de desistência da carreira - ainda no início da carreira (ROCHA, 2016). Com base na realidade do tempo relacionado ao plano de carreira do professor brasileiro, as marcações temporais não se encaixam. Hubermam (2000) apresenta uma carreira dada em cerca de 40 a 50 anos de tempo de serviço. Esse recorte está acima do condicionado ao professor da educação básica de nosso país, que compreende o período entre 25 e 35 anos de atuação. Não há registro de estudos encontrados que nos dão aporte epistemológico sobre a relação temporal com as fases da carreira, que atenda às especificidades do professor brasileiro, o que abre espaço e indagações para uma possível perspectiva sociológica de análise.

Entendendo que a sobrevivência se refere ao choque real das diversidades encontradas em sala de aula, trazendo à tona um confronto com a complexidade da situação profissional, que lida diretamente com o social. Paralelamente, o estado de descoberta permite os professores iniciantes aguentar o estado da sobrevivência, por enaltecer o entusiasmo inicial, a experimentação, a exaltação por estar na escola na condição de professor, e a responsabilidade com que se depara. O período de iniciação é recorrente ao período de ligação entre a formação inicial e o desenvolvimento profissional, e possui características muito próprias (GARCIA, 1999; PAPI, 2011). A aprendizagem do tipo ensaio-erro (VAILLANT e MARCELO, 2012) é vivenciada com uma intensidade que consideramos exacerbada, e é uma das características marcantes da sobrevivência, e por um predomínio do valor prático: o professor quer dar conta do ensino 
e aprendizagem do conteúdo, quando, na verdade, ele mesmo ainda está aprendendo a ensinar.

O mais alarmante dessa fase da carreira é a imitação de práticas de ensino dos conteúdos, de professores mais experientes, sem que o professor reflita o processo de ensino-aprendizagem dos conteúdos como parte de uma totalidade e contexto na qual a comunidade escolar está inserida. A aprendizagem, tanto de alunos como de professores, é reproduzida de forma acrítica. Evidenciamos o nosso entendimento de que a responsabilidade desse alarde não restringe sua responsabilidade ao professorado em si, mas também no investimento e na formação e desenvolvimento profissional docente, contida em um projeto de escola.

Esse movimento inquietante do exercício pedagógico também é o momento em que os docentes começam a conhecer o cotidiano escolar, em que a socialização tem elementos conflituosos, importante de serem observados, por também ser a responsável, em nossa leitura, pelos impactos do choque de realidade e descobertas. "Nesse momento, os novos docentes interiorizam as normas, valores e condutas que caracterizam a cultura escolar na qual se integram" (VAILLANT e MARCELO, 2012, p. 132). Para dar continuidade a esse estudo, partimos do conceito de socialização como o processo que media a aquisição de conhecimento e as destrezas sociais (PAPI 2011; VAILLANT e MARCELO, 2012), essenciais na organização das funções cabíveis ao exercício da docência.

Com base em Curado Silva (2012) para entender que a função social do professor está na premissa em trabalhar com a aprendizagem do conhecimento, para a formação humana, com capacidades e habilitações em dominar conteúdos científicos e culturais, propositivos para a sua relação e interação social e política.

A função social do professor relaciona-se à da escola. A escola é uma instância social, entre outras, que tem um papel mediador em um projeto de sociedade, que tanto pode ser conservador como transformador, por isso também contraditória entre formar para o mercado de trabalho ou numa perspectiva omnilateral. Nesse sentido, a função básica da escola é: ocupar-se da formação do homem, capaz de entender, interpretar e transformar o mundo em que vive; oferecer o domínio de determinados conteúdos científicos e culturais, a fim de garantir a aprendizagem de conhecimentos, habilidades e valores, necessários à socialização do indivíduo. As aprendizagens devem constituir-se em instrumentos e habilidades para que o aluno compreenda melhor a realidade que o cerca, favorecendo sua participação em relações sociais cada vez mais amplas, possibilitando a leitura e interpretação das informações que hoje são amplamente veiculadas (CURADO SILVA, 2012, p. 203). 
A complexidade está detalhada no fato de que o docente iniciante ainda está na transição do estranhamento com as normas e símbolos, códigos construídos para estabelecer uma organização na rotina escolar e na relação professor-aluno, e que só vão sendo familiarizadas pouco a pouco. O complexo está nesse familiarizar-se pouco a роисо: da mesma forma que lançamos questionamentos sobre o professor imitar práticas, num molde de reprodução, sem estranhar, refletir e percebê-las de formas críticas (o que não significa dispensar ou rejeitar o que se aprende com os colegas que tem mais tempo de carreira), em um movimento ligado à práxis.

Essa relação da reprodução do fazer pedagógico se revela como um fenômeno objetivo-subjetivo, em que há fatores das relações sociais no cotidiano escolar. Cabem questionamentos para entender que, muito mais relevante do que responder o que estão fazendo, é compreender por que a imitação sem uma reflexão: seria por insegurança sobre o como ensinar, ou ainda para evitar confrontos epistemológicos e metodológicos de um projeto de escola que se defenda, por exemplo.

Esses processos se emaranham ainda, nas funções com que o professor tem que exercer, e as tarefas que têm que cumprir:

devem ensinar e devem aprender a ensinar. [...] adquirir conhecimentos sobre os estudantes, o currículo e o contexto escolar; planejar adequadamente o currículo e o ensino; começar a desenvolver um repertório docente que lhes permita sobreviver como professor; criar uma comunidade de aprendizagem na sala de aula e continuar desenvolvendo uma identidade profissional (VAILLANT, MARCELO, 2012, p. 131).

Todas essas tarefas e funções, com as mesmas responsabilidades e com a mesma carga horária que docentes mais experientes, e ainda subjugados a condições de turmas enredadas com dificuldades variadas. Variantes que se revelam para nós como parte dos fenômenos objetivos que intensificam a fase inicial da carreira. Aos docentes iniciantes, estão incumbidas, na maioria dos casos, a prova de fogo de trabalhar em instituições escolares mais complexas, e em condições e horários descartados para os que têm mais tempo de carreira. Essas eloquências geram um alto custo social e político para a classe trabalhadora e que frequenta a escola pública.

Devido às especificidades desta fase, sobretudo das sobrevivências e descobertas, a iniciação à docência tem sido tratada com cautela para a constituição basilar na configuração das ações profissionais e para a permanência do profissional na docência, em diversos países da Europa, estabelecendo-se um apoio diferenciado ao professor iniciante, assumindo que nesse período há "uma aproximação tanto de fatores pessoais quanto de fatores e aspectos profissionais, estruturais e organizacionais com os quais se defronta o professor" (PAPI e MARTINS, 2010). 
Em geral, esses países oferecem medidas formais de introdução, orientação, assessoriamente e adaptação gradual. Papi (2011), por exemplo, destaca que em Portugal há um apoio ofertado por um professor titular com formação específica, de perfil similar ao do ingressante, trabalhando no plano didático e científico, demandando contribuição para uma educação de qualidade.

\section{A empiria das pesquisas brasileiras sobre professores iniciantes no Brasil: revisão literária}

A partir dos dados sistematizados, apresentados por etapas, elaboramos a seguir um comparativo geral, expondo uma análise em cima de categorias de análise reveladas a partir dos dados obtidos, no qual totalizamos 30 pesquisas no banco de dados do IBICT, 58 entre os anais dos eventos selecionados; e 39 artigos publicados nos periódicos Qualis A e B, tangenciando 127 pesquisas sobre o professor no início de carreira. O período de recorte temporal para esta busca se deu entre os anos de 2000-2014. Todo o levantamento segue sistematizado nas Tabelas 1, 2 e 3, organizadas por lócus de publicação.

\begin{tabular}{|c|c|c|c|}
\hline \multicolumn{4}{|c|}{ Tabela 1 - Publicações - Teses e Dissertações } \\
\hline CATEGORIA & NIVEL & $\begin{array}{l}\text { QUANTIDADE } \\
\text { POR NIVEL }\end{array}$ & $\begin{array}{l}\text { QUANTIDADE } \\
\text { TOTAL }\end{array}$ \\
\hline \multirow{2}{*}{$\begin{array}{l}\text { Condição de } \\
\text { Trabalho }\end{array}$} & $\begin{array}{l}\text { Dissertações de } \\
\text { Mestrado }\end{array}$ & 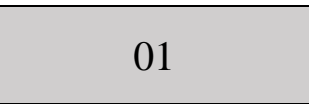 & \multirow[t]{2}{*}{01} \\
\hline & Tese de Doutorado & -- & \\
\hline \multirow{2}{*}{$\begin{array}{l}\text { Exercício } \\
\text { Profissional }\end{array}$} & $\begin{array}{l}\text { Dissertações de } \\
\text { Mestrado }\end{array}$ & 10 & \multirow[t]{2}{*}{11} \\
\hline & Tese de Doutorado & 01 & \\
\hline \multirow{2}{*}{$\begin{array}{l}\text { Professor Iniciante } \\
\text { por Especialidade }\end{array}$} & $\begin{array}{l}\text { Dissertações de } \\
\text { Mestrado }\end{array}$ & 08 & \multirow[t]{2}{*}{10} \\
\hline & Tese de Doutorado & 02 & \\
\hline \multirow[t]{2}{*}{ Profissionalidade } & $\begin{array}{l}\text { Dissertações de } \\
\text { Mestrado }\end{array}$ & -- & \multirow[t]{2}{*}{01} \\
\hline & Tese de Doutorado & 01 & \\
\hline \multirow{2}{*}{$\begin{array}{l}\text { Programa de } \\
\text { Iniciação à } \\
\text { Docência }\end{array}$} & $\begin{array}{l}\text { Dissertações de } \\
\text { Mestrado }\end{array}$ & 02 & \multirow[t]{2}{*}{04} \\
\hline & Tese de Doutorado & 02 & \\
\hline \multirow{2}{*}{$\begin{array}{l}\text { Revisão de } \\
\text { Literatura }\end{array}$} & $\begin{array}{l}\text { Dissertações de } \\
\text { Mestrado }\end{array}$ & 01 & \multirow[t]{2}{*}{01} \\
\hline & Tese de Doutorado & -- & \\
\hline \multirow[t]{2}{*}{ Socialização escolar } & $\begin{array}{l}\text { Dissertações de } \\
\text { Mestrado }\end{array}$ & 01 & \multirow[t]{2}{*}{$\mathbf{0 2}$} \\
\hline & Tese de Doutorado & 01 & \\
\hline \multicolumn{3}{|c|}{$\begin{array}{ll} & \text { TOTAL } \\
\end{array}$} & 30 \\
\hline
\end{tabular}


Enquanto a Tabela 1 traz a classificação por categoria das 30 Teses de Doutorado e Dissertações de Mestrado, a Tabela 2, a seguir, traz a distribuição por categorias das 58 publicações realizadas em Anais de Eventos.

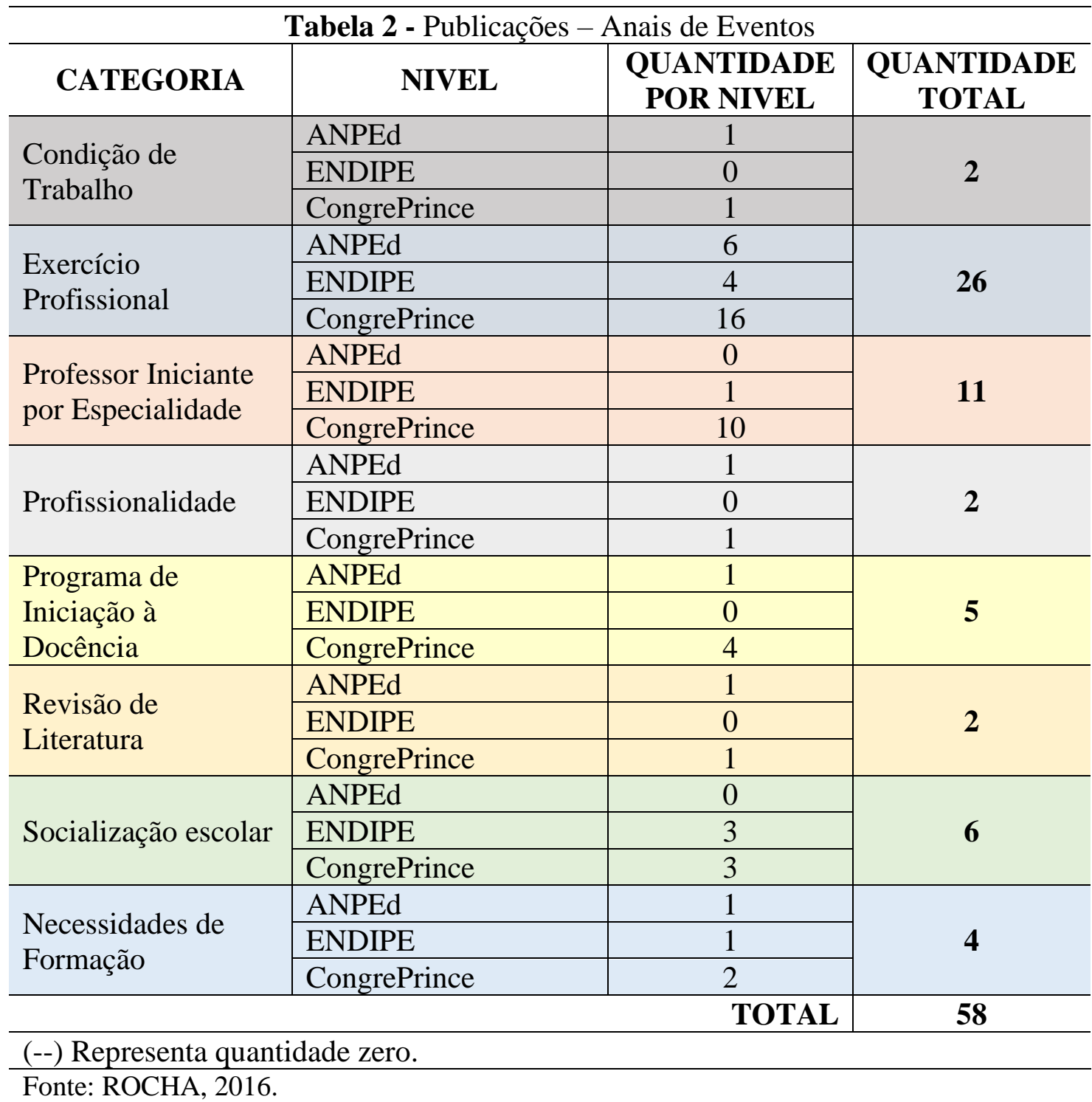

Temos ainda, na Tabela 3, a classificação das 39 publicações em periódicos Qualis A e B, segundo as oito (8) categorias: Condição de Trabalho; Exercício Profissional; Professor Iniciante por Especialidade; Profissionalidade; Programa de Iniciação à Docência; Revisão de Literatura; Socialização escolar; e Necessidades de Formação. O conjunto das três tabelas nos ajuda a mapear o objeto da investigação. 


\begin{tabular}{|c|c|c|c|}
\hline \multicolumn{4}{|c|}{ Tabela 3 - Publicações - Periódicos Qualis A e B } \\
\hline CATEGORIA & NIVEL & $\begin{array}{l}\text { QUANTIDADE } \\
\text { POR NIVEL }\end{array}$ & $\begin{array}{l}\text { QUANTIDADE } \\
\text { TOTAL }\end{array}$ \\
\hline \multirow{2}{*}{$\begin{array}{l}\text { Exercício } \\
\text { Profissional }\end{array}$} & Periódicos Qualis A & 3 & \multirow{2}{*}{13} \\
\hline & Periódicos Qualis B & 10 & \\
\hline \multirow{2}{*}{$\begin{array}{l}\text { Professor Iniciante } \\
\text { por Especialidade }\end{array}$} & Periódicos Qualis A & 1 & \multirow{2}{*}{6} \\
\hline & Periódicos Qualis B & 5 & \\
\hline \multirow{2}{*}{ Profissionalidade } & Periódicos Qualis A & 1 & \multirow{2}{*}{2} \\
\hline & Periódicos Qualis B & 1 & \\
\hline \multirow{2}{*}{$\begin{array}{l}\text { Programa de } \\
\text { Iniciação à Docência }\end{array}$} & Periódicos Qualis A & 2 & \multirow{2}{*}{7} \\
\hline & Periódicos Qualis B & 5 & \\
\hline \multirow{2}{*}{ Revisão de Literatura } & Periódicos Qualis A & 1 & \multirow{2}{*}{6} \\
\hline & Periódicos Qualis B & 5 & \\
\hline \multirow{2}{*}{ Socialização Escolar } & Periódicos Qualis A & 1 & \multirow{2}{*}{1} \\
\hline & Periódicos Qualis B & 0 & \\
\hline \multirow{2}{*}{ Identidade } & Periódicos Qualis A & 1 & \multirow{2}{*}{1} \\
\hline & Periódicos Qualis B & 0 & \\
\hline \multirow{2}{*}{$\begin{array}{l}\text { Representações } \\
\text { Sociais }\end{array}$} & Periódicos Qualis A & 1 & \multirow{2}{*}{3} \\
\hline & Periódicos Qualis B & 2 & \\
\hline & & TOTAL & 39 \\
\hline
\end{tabular}

(--) Representa quantidade zero.

Fonte: ROCHA, 2016.

Entre as pesquisas, percebemos um maior interesse pela categoria do exercício profissional, que em linhas gerais, os 46 trabalhos localizados tratam da aprendizagem da docência, desenvolvimento profissional, saberes docentes, prática docente, experiências, descobertas, dificuldades e desafios e de necessidades formativas da inicialização à carreira docente. As pesquisas apontam para uma formação e uma prática de modo particularmente subjetivo ao professor, o que nos permite perceber que a totalidade das imersões objetivas as quais a profissão docente está submetida, e revelada pelos questionamentos a partir da teoria exposta até aqui, nos permitindo questionar sobre a realização de uma análise presa à aparência centrada na prática do exercício profissional, no cotidiano escolar.

Há também um grande interesse manifestado nas 27 pesquisas que tratam do professor iniciante das licenciaturas de áreas específicas, trazendo um grande apontamento a falhas na formação pedagógica, básica para o exercício profissional, que se relacionam a abordagem as 46 investigações citadas na categoria do exercício profissional.

Outros 16 trabalhos apontam iniciativas brasileiras de programas de iniciação à docência, permitindo fazer um apanhado geral sobre a necessidade de haver uma política pública que se preocupe com o desenvolvimento profissional docente e a passagem da formação inicial para o início na carreira. Nove trabalhos tratam da socialização escolar, 
estabelecendo questionamentos relacionados à parceria e hierarquias imbricadas nas escolas, e pesando a cultura escolar, para os impactos positivos e negativos ao início à carreira docente. Outros nove trabalhos relatam uma revisão de literatura sobre as pesquisas levantadas sobre a nossa temática, em diversas fontes de pesquisas, com recortes temporais diferenciados. Há cinco trabalhos que tratam sobre a constituição da profissionalidade, de um modo particularmente ligado ao exercício profissional cotidiano, também, sob a análise da subjetividade, escanteando a totalidade da profissão docente. Em contrapartida, apenas um trabalho enfoca na identidade profissional, do professor, partindo do sujeito iniciante na carreira, como objeto do estudo.

Há quatro pesquisas vão tratar especificamente das necessidades formativas do professor iniciante, também sob o foco e a ótica da prática docente. Três pesquisas vão abordar a condição de trabalho, levantando questionamentos importantes sob quais circunstâncias os professores iniciam na profissão, e por isso, as dificuldades e choque de realidade que enfrentam nessa fase. Outras três pesquisas vão discutir as representações sociais do que é ser professor, trabalhando como foco no professor iniciante, e os conceitos estabelecidos sobre a profissão: aqui, os termos vocacionados à docência e a subjetividade aparecem, ignorando a totalidade, e a perspectiva de que o sujeito torna-se professor.

No "Gráfico 01: Quantidade de publicações sobre professor iniciante por categoria.", sistematizamos essa análise geral das categorias as quais as pesquisas se apresentam, permitindo uma melhor visualização do que as pesquisas tratam em seus trabalhos, revelando um comparativo qualitativo e quantitativo.

Gráfico 1 - Quantidade de publicações sobre professor iniciante por categoria.

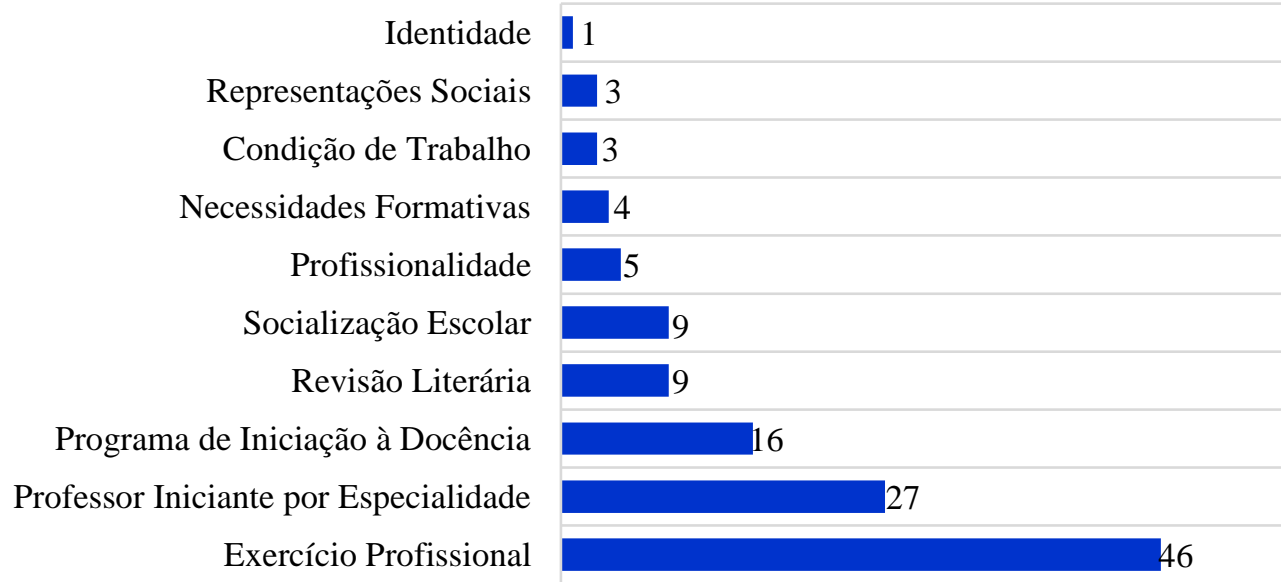

Fonte: GEPFAPe. Organização: ROCHA, 2016. 
Entre os artigos publicados nos periódicos e em anais de eventos, fazendo uma sistematização simples por busca de palavras-chave, percebemos que dos 96 trabalhos publicados nessas duas fontes de pesquisa, 46 trabalhos pertencem aos mesmos autores. Dentre estes pesquisadores, apenas um deles é citado como autor de uma das dissertações.

Quando nos atentamos para as instituições descobrimos um quantitativo de 57 instituições que tem estudado a temática, sendo a grande maioria concentrada na região Sudeste, representando 59,41\%, dentre as quais, 13 instituições são do estado de São Paulo. Outras cinco no Rio de Janeiro e Minas Gerais, e uma no estado do Espírito Santo. Em seguida, a Região Sul traz um quantitativo representado em 32,97\%, divididos em sete instituições no Paraná, seis em Santa Catarina e cinco no Rio Grande do Sul.

A região Centro-Oeste com o uma porcentagem de 11,88\%, revela um menor número de instituições envolvidas, sendo três no Mato Grosso do Sul, uma no Mato Grosso, uma no Distrito Federal e uma no Goiás. A região Nordeste tem um menor quantitativo de pesquisas publicadas, com percentual de $6,32 \%$, entre três instituições na Bahia, duas no Piauí e uma em Pernambuco. Nenhuma pesquisa foi referida a uma instituição localizada no norte do país.

Gráfico 2 - Quantidade de publicações sobre professor iniciante por região

\begin{tabular}{|c|c|}
\hline Não cita a instituição & 3,17 \\
\hline Europa & 1,58 \\
\hline Norte & 0 \\
\hline Nordeste & 6,32 \\
\hline Centro-Oeste & 11,88 \\
\hline Sul & 32,97 \\
\hline Sudeste & 59,41 \\
\hline
\end{tabular}

Fonte: GEPFAPe. Organização: ROCHA, 2016.

Sobre os enfoques metodológicas, o "Gráfico 3: Quantidade de publicações sobre professor iniciante por abordagens e modalidades” permite visualizar a síntese dos caminhos metodológicos escolhidos para tratar sobre o objeto de estudo e os objetivos traçados: 50 pesquisas utilizam de uma base qualitativa, sendo que uma assume a base qualitativa e quantitativa. E ainda, 24 se embasam em estudos narrativos, 14 utilizam da 
(auto)biografia, 11 de estudos de caso, seis da metodologia de pesquisa formativa, cinco da descritivo-analítica, cinco da interpretativa, cinco da pesquisa-ação, três da exploratória, três de história de vida, três da investigativa, duas da etnografia, uma faz estudo comparativo, um estudo teórico. Ainda encontramos duas pesquisas que utilizam o survey, 16 que realizam uma revisão bibliográfica, e 24 não assumem a abordagem da investigação.

Gráfico 3 - Quantidade de publicações sobre professor iniciante por abordagens e modalidades

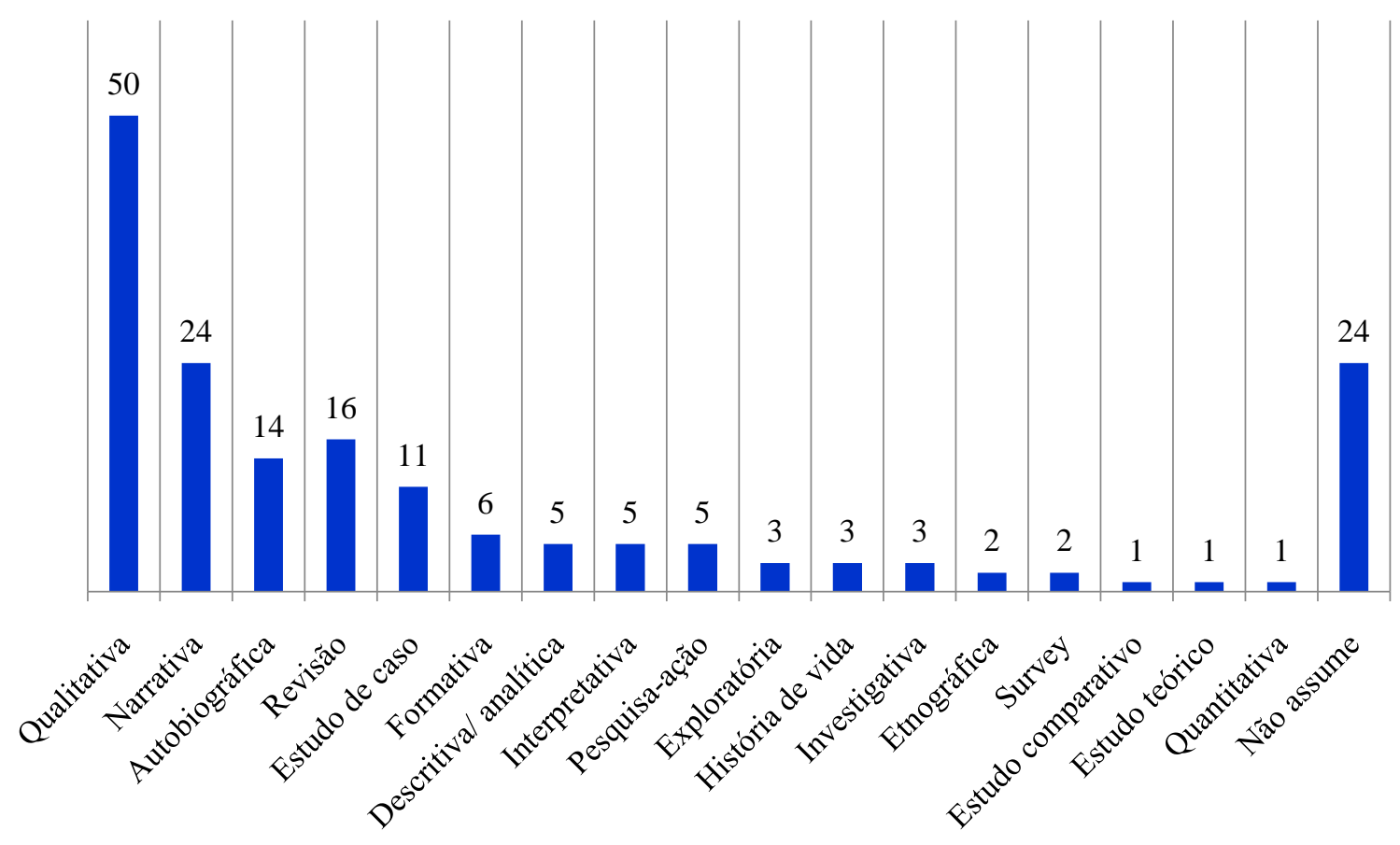

Fonte: GEPFAPe. Organização: ROCHA, 2016.

Sobre os instrumentos de pesquisa utilizados, conforme demonstrado no "Quadro 2: Instrumentos de Pesquisa", percebemos a utilização, em sua maior parte, da entrevista em 56 pesquisas, seguida de 30 estudos que utilizam do questionário, e 27 de diário de campo ou escritos individuais como similares, 18 trabalhos utilizam da observação, 11 de grupos de diálogo ou pesquisa, ou técnicas similares, nove realizam pesquisa documental, seis do grupo focal e duas de rodas de conversa. Uma pesquisa não esclarece qual o instrumento utilizado para a investigação. 
Gráfico 4 - Quantidade de publicações sobre professor iniciante por instrumentos de pesquisa

\begin{tabular}{|c|c|}
\hline Não esclarece & 1 \\
\hline Roda de conversa & a 2 \\
\hline Grupo focal & 6 \\
\hline Pesquisa documental & 9 \\
\hline Grupo de diálogo ou pesquisa & 11 \\
\hline Observação & 18 \\
\hline Diário & 27 \\
\hline Questionário & 30 \\
\hline Entrevista & 56 \\
\hline
\end{tabular}

Fonte: GEPFAPe. Organização: ROCHA, 2016.

Entre os principais autores e estudiosos referenciados nas pesquisas levantadas para fundamentar o desenvolvimento profissional docente e a aprendizagem da docência no início da carreira, percebemos uma grande utilização de estudos de António Nóvoa, Bernadete Gatti, Carlos Marcelo García, Donald Shön, José Carlos Libâneo, Kenneth Zeichner, Lee Shulman, Maurice Tardif e Michael Huberman. Classificados em um segundo grupo, de menos utilizados que os autores já citados, identificamos Bernard Charlot, Helena de Freitas, Henry Giroux, Iria Brzezinski, Lev Semenovitch Vigotski, Luiz Carlos de Freitas, Miguel Arroyo, Paulo Freire, Selma Garrido Pimenta e Vera Maria Candau.

\section{Algumas lacunas e considerações para o debate}

A partir do conhecimento proporcionado nesta revisão literária, a empiria das pesquisas brasileiras sobre a temática do professor iniciante não traz nenhuma investigação que se debruce em entender diversas lacunas sobre o início da carreira, alocando o trabalho docente enquanto categoria analítica, tornando nosso desafio maior, em apanhar as mediações que compõe o nosso objeto de estudo, mas que permite nos orientar, reconhecendo que há uma produção de conhecimento acumulada. A incipiência de pesquisas que façam um trabalho em cima de um programa de recepção dos professores iniciantes na carreira, por exemplo, e de uma política pública em evidência, confirma o não investimento de ações políticas-pedagógicas para os profissionais do trabalho docente, especialmente, os que ingressam no magistério público. 
As ações de inserção profissional, mencionados por Papi (2011) em países europeus, são programas intencionados com as atividades pontuais dos professores, e que podem ser levadas, a sua oferta, em diversas escolas que recebem esses profissionais para a entrada na carreira. Porém, partindo dos estudos referenciados em Papi (2011) e Vaillant e Marcelo (2012), esses programas, no geral, conseguem cumprir a função burocrática do receber esses professores iniciantes, mas não contribuem para criar a identidade profissional, essencial para o exercício profissional pedagógico, e pelo discernimento quanto às políticas de valorização à carreira e condições de trabalho, tão impactantes ao cotidiano escolar. $\mathrm{O}$ próprio fato de haver incipiência de programas de inserção na carreira, que não contribua para a formação da identidade, poderá acarretar impacto e influenciar na própria construção de um projeto de escola por estes docentes, na fase inicial da profissão e contribuir para a desistência da carreira.

A passividade quanto às fragilidades nas ações de inserção do profissional na carreira pode acarretar no abandono do conhecimento obtido na formação inicial. O que, em nossa opinião, contribuem para uma formação docente subjetiva, fragmentada das relações dialéticas de subjetividade-objetividade, intencionando para uma formação em serviço; e com foco na epistemologia da prática condicionante a um fazer reprodutor de conhecimento e que rompe com o princípio de que o professor é, se não, o profissional que lida com a aprendizagem da produção de conhecimento, e, portanto, produtor do seu objeto de trabalho. Essas consequências agravam no afastamento tangenciado da escola de educação básica com as universidades.

Além do que, não se atentar as especificidades dos problemas relacionados à fase de início da carreira, pode acarretar o abandono da carreira, ou mesmo na desistência da profissão, mesmo em exercício, e impactando na confiança das próprias competências e saberes adquiridos, gerando um ressentir na relação professor-aluno. Ou seja, as escolhas futuras dos professores, ao longo do desenvolvimento profissional, estão diretamente ligadas aos impactos sofridos e vivenciados nesta primeira fase.

Chamamos a atenção para o fato de que a omissão quanto a posicionamentos concretos quanto à realidade da condição de trabalho, ocasionam na ampliação das responsabilidades docentes, da jornada de trabalho sem reajustes e da intensificação do trabalho, reforçando a condição da proletarização da categoria do professorado, além de causar uma objetividade no desinteresse e na desistência da profissão (KUENZER; CALDAS, 2009; OLIVEIRA, 2004).

É preciso entender o trabalho como instância ontológica, e, evidenciar, que é essa ontologia do ser social em determinadas condições históricas relaciona-se diretamente como parte da formação da classe, uma característica propiciadora para a consciência de classe e das pressões insanas lançadas sobre o trabalho do professorado. Nesse sentido a 
produção de conhecimento e a pesquisa como parte do trabalho ontológico dos sujeitos professores não podem se prender ao imediato (MORAES; TORRIGLIA, 2003), o que cabe posturas de resistência e militância.

Exemplificando no campo da educação, como o trabalho do professor, o produto final que o capitalismo espera é uma mão de obra qualificada para o seu "uso", por vias baratas. Não se investe na formação e na carreira dos professores da educação básica como uma formação contínua que deve acompanhar seu tempo, centrada na formação humana e humanizadora.

Essas relações condicionam ao trabalho docente - produtor de conhecimento - a limitação de seu trabalho. No capitalismo, tudo carece estar mantido em relações de controle, para que sua ordem mercantilista se mantenha forte. Assim, também se limita sua formação e sua condição de atuar. E por isto, desta lacuna ocasionada a partir da pouca ou quase nula discussão do trabalho docente enquanto categoria se abre um leque para outras novas compreensões e apreensões, possibilitadoras de uma formação de professores iniciantes fortalecida por um projeto que permita concretizar a unicidade da teoria-prática.

\section{Referências}

CURADO SILVA, K. A. P. C. Políticas Públicas na Formação de Professores e a Relação Teoria e Prática: um debate com Gramsci. In: CUNHA, Célio; SOUSA, José V.; SILVA, Maria Abádia (Orgs.). Avaliação de Políticas Públicas de Educação. Brasília: Faculdade de Educação, Universidade de Brasília; Líber Livro, 2012.

GARCIA, M. Formação de Professores: para uma mudança educativa. Porto: Porto, 1999.

HUBERMAN, M. O Ciclo de Vida Profissional dos Professores. In: NÓVOA, António (Org.). Vida de Professores. Porto: Porto Editora, 2000, p. 31-62.

KUENZER, A. Z.; CALDAS, A. Trabalho docente: comprometimento e desistência. In: OLIVEIRA, Maria Auxiliadora M.; FIDALGO, Nara Luciene Rocha (Orgs.). A intensificação do trabalho docente: tecnologias e produtividade. Campinas, SP: Papirus, p. 19-48, 2009.

MORAES, M. C. M. de; TORRIGLIA, P. L. Sentidos de ser docente e da construção de seu conhecimento. In: MORAES, Maria Célia Marcondes de (Org.). Iluminismo às avessas. Produção de conhecimento e políticas de formação docente. Rio de Janeiro: DP\&A, 2003, p. 45-60.

OLIVEIRA, D. A.; VIEIRA, L. F. Condições de trabalho docente: uma análise a partir de dados de sete estados brasileiros. In OLIVEIRA, D. A.; VIEIRA, L. F. (Org.). 
Trabalho na educação básica: a condição docente em sete estados brasileiros. Belo Horizonte, MG: Fino Traço, p. 153-190, 2012.

OLIVEIRA, D. A. A reestruturação do trabalho docente: precarização e flexibilização. Educação \& Sociedade. Campinas, vol. 25, n. 89, p. 1127-1144, Set./Dez. 2004.

PAPI, S. O. G. Professoras Iniciantes bem-sucedidas: um estudo sobre seu desenvolvimento profissional. Tese de Doutorado, PUC-PR: Curitiba, 2011.

PAPI, S.; MARTINS, P. L. As Pesquisas sobre Professores Iniciantes: algumas aproximações. In: Educação em Revista. v. 26, n. 02, 2010, p. 39-56.

PISTRAK, M. M. Fundamentos da Escola do Trabalho. São Paulo: Ed. Expressão Popular: $6^{\mathrm{a}}$ reimpressão, 2008.

ROCHA, D. R. Os Sentidos Políticos Atribuídos à Educação Escolar pelos Professores Iniciantes: continuidade, utopia, resistência e revolução. 2016. 209f. Dissertação (Mestrado em Educação) - Faculdade de Educação, Universidade de Brasília, Brasília, 2016.

VAILLANT, D.; MARCELO, C. Ensinando a ensinar: as quatro etapas de uma aprendizagem. Curitiba: Ed. UTFPR, 2012.

Recebido em: 21 mar. 2020. Aprovado em: 11 jun. 2020.

*Deise Ramos da Rocha é doutora em Educação pela Universidade Federal de Pelotas (UFPel). Pedagoga e Mestre em Educação pela Universidade de Brasília (UnB). Membro pesquisadora do CEPE/UFPel (Centro de estudos em Políticas Educativas) e do GEPFAPe/UnB (Grupo de Estudos e Pesquisas sobre a Formação e Atuação de Pedagogos/Professores). Professora da Secretaria de Educação do Distrito Federal (SEDF).

E-mail: deise.rocha@hotmail.com

https://orcid.org/0000-0002-5608-9425 